\title{
O USO DE LINGUAGEM DE INDEXAÇÃO POR BIBLIOTECAS UNIVERSITÁRIAS BRASILEIRAS
}

\section{THE USE OF INDEXING LANGUAGES BY BRAZILIAN UNIVERSITY LIBRARIES}

Maria Carolina Andrade Cruz ${ }^{a}$

Mariângela Spotti Lopes Fujitab

\begin{abstract}
RESUMO
Introdução: As linguagens de indexação têm como propósito alcançar o controle de vocabulário nos catálogos das bibliotecas em função da organização e recuperação da informação. Com isso, este trabalho configura-se em estudo analítico sobre o uso das linguagens de indexação em bibliotecas universitárias brasileiras. Objetivo: Uma perspectiva ampla do emprego das ferramentas de controle de vocabulário ao investigar como as bibliotecas universitárias brasileiras utilizam as linguagens de indexação. Metodologia: Método de pesquisa de cunho exploratório com o uso de questionário como instrumento de coleta de dados. Elaboração de categorias de análise a partir das respostas obtidas e dos objetivos traçados. Resultados: Totalizaram-se 46 respostas obtidas por meio da aplicação do questionário. Recuperou-se respostas de todos os estados brasileiros. Conclusões: As bibliotecas estão cientes da importância do controle de vocabulário, pois em sua maioria utilizam linguagem de indexação no tratamento da informação. Contudo, requer o estabelecimento de procedimentos consistentes quando não encontrado o termo na linguagem utilizada.
\end{abstract}

Descritores: Organização da Informação. Linguagem de indexação. Controle de vocabulário. Bibliotecas universitárias.

\section{INTRODUÇÃO}

As bibliotecas exercem a competência em organizar a informação registrada por procedimentos de representação. A tarefa de organização a partir da representação da informação pela indexação é uma tarefa complexa compreendida na esfera do tratamento temático da informação. Por isso, os

\footnotetext{
a Doutoranda no Programa de Pós-Graduação em Ciência da Informação da Universidade Estadual Paulista (UNESP). Bibliotecária na Associação Santa Marcelina, na unidade de Botucatu. E-mail: maria.andradeecruz@gmail.com

b Doutora em Ciências da Comunicação pela Universidade de São Paulo (USP). Docente do Programa de Pós-graduação em Ciência da Informação da Universidade Estadual Paulista (UNESP). E-mail: mariangela.fujita@unesp.br
} 
indexadores precisam estabelecer procedimentos e ferramentas consistentes para "desvendar" o assunto dos documentos a fim de representar a informação atribuída a eles.

Compreende-se como uma ferramenta para a representação da informação as linguagens de indexação utilizadas no processo de indexação. As linguagens de indexação representam o conteúdo dos documentos em uma linguagem controlada ao sistema utilizado. Percebe-se que sem a mediação dessa ferramenta, a recuperação objetiva da informação aos interesses do usuário fica inviável e o sistema inconsistente, devido à falta de controle de vocabulário.

O estudo de Fujita et al. (2019) buscou realizar um estudo analítico, em bibliotecas universitárias do sudeste do Brasil, a fim de verificar o uso das linguagens de indexação por profissionais responsáveis pela indexação, além da presença de um manual de política de indexação e aspectos sobre a construção de uma linguagem de indexação própria da instituição, como o software utilizado e procedimentos para a sua manutenção.

Desse modo, as autoras reuniram 60 questionários respondidos, na qual observaram-se os seguintes resultados: $60 \%$ possui coleções especializadas de uma até quatro áreas de assunto, $73 \%$ das bibliotecas têm de 1 a 3 profissionais dedicados à indexação, 83\% das bibliotecas integram uma rede ou sistema, 50\% participam de catálogos coletivos. Com relação ao uso, verificou-se que 49 $(89,1 \%)$ utilizam alguma linguagem de indexação, 25 (51\%) utilizam uma linguagem de indexação, sendo $20 \mathrm{com}$ linguagem própria sem uso de software específico para construção e manutenção, e 24 (49\%) mais de uma linguagem. Sobre os procedimentos utilizados quando não encontrado o termo preferido na linguagem de indexação utilizada, verificou-se que 17 bibliotecas adicionam os novos termos em linguagem natural, 14 delas adequam os termos a outros já existentes, com a atribuição à um termo geral, 11 respondentes adicionam os termos novos mediante a estudo em grupo para a adequação ou adição dos mesmos, e por último, dentre as 49 bibliotecas que utilizam linguagem de indexação, 19 adicionam novos termos mediante pesquisa em outros catálogos, sem compartilhar a decisão com um grupo gestor. 
A manutenção da linguagem de indexação mediante a interoperabilidade semântica é feita por 17 bibliotecas dentre as 60 analisadas. A formalização da política de indexação em documento é realizada por 35 bibliotecas $(58,3 \%)$, sendo que oito delas não descrevem sobre a linguagem de indexação.

Tendo em vista o recorte feito no trabalho de Fujita et al. (2019), nas bibliotecas do sudeste brasileiro, estabelece a questão desta pesquisa em verificar como as bibliotecas universitárias do Brasil fazem o uso da linguagem de indexação.

Com isso, define-se como objetivo investigar como as bibliotecas universitárias brasileiras utilizam as linguagens de indexação a partir de estudo analítico, buscando uma perspectiva ampla do emprego das ferramentas de controle de vocabulário.

Para atingir o objetivo traçado e tendo como norteador a questão de pesquisa, houve a aplicação de questionário às bibliotecas universitárias e foi possível reunir uma amostra de todos os estados brasileiros.

\section{LINGUAGEM DE INDEXAÇÃO NO ÂMBITO DA ORGANIZAÇÃO DA INFORMAÇÃO}

A Ciência da Informação vem buscando, por meio dos pesquisadores e profissionais da área, novas técnicas de organização e representação da informação, em diferentes formatos. Segundo Svenonius (2000) a organização da informação é um trabalho tradicional feito no campo da Biblioteconomia, Ciência da Informação e em Organização do Conhecimento. De fato, na Biblioteconomia, a organização da informação é um trabalho diário das bibliotecas, pois se almeja organizar a informação física e temática dos documentos para fins de recuperação.

Chowhury (2004) reforça que o sucesso no acesso à informação depende da organização e representação da informação. Sendo assim, os bibliotecários não buscam apenas fazer com que o acervo da biblioteca esteja organizado nas estantes, mas também com que os catálogos das bibliotecas sejam padronizados e consistentes para bom aproveitamento dos recursos oferecidos.

Ao estabelecer a organização da informação é necessário um tratamento 
específico para cada função, chamado de tratamento da informação no qual abrange disciplinas e metodologias responsáveis por descrever materiais bibliográficos (REDIGOLO, 2010), são duas tipologias encontradas: o tratamento descritivo, responsável por identificar e organizar informações extrínsecas aos documentos, como autoria, título, data de publicação, etc.; e o tratamento temático, que lida com o processo de identificação do conteúdo/assunto intrínsecos aos documentos (DIAS; NAVES, 2007; SOUZA; HILLESHEIM, 2014). É possível perceber que ambas as esferas de tratamento da informação estão diretamente ligadas à organização e recuperação da informação, mudando apenas a abordagem de tratamento. $O$ tratamento temático da informação compreende o processo de indexação, na qual são reunidos os procedimentos de análise de assunto, seleção de conceitos e a tradução em termos de indexação.

Segundo Albrechtsen (1993) a análise de assunto é um procedimento adotado por indexadores para designar termos de indexação na descrição de objetos informacionais. A análise do documento é feita mediante uma leitura técnica do indexador, buscando identificar conceitos que o descrevem. É realizada a atribuição de termos representativos, ou seja, são selecionados os termos que representam o documento e traduzidos a partir do uso de uma linguagem de indexação para termos padronizados pelo sistema adotado. Portanto, o processo de indexação configura-se essencialmente na análise de assunto, na qual serão identificados e selecionados os termos que melhor correspondem ao tema do documento e sua representação através de uma linguagem de indexação (MAI, 2001; GIL LEIVA, 2008; CLEVELAND; CLEVELAND, 2013; FUJITA, 2013).

\subsection{LINGUAGEM DE INDEXAÇÃO}

As linguagens de indexação recebem esse nome pois são ferramentas particulares à sua utilização em bibliotecas, especialmente no setor de indexação. Representam linguagens artificiais construídas com o objetivo de descrever o assunto dos documentos por meio de termos controlados para determinado sistema e comunidade. O termo "linguagem de indexação" está 
articulado ao processo de indexação, pois se configura em ferramenta para descrição e recuperação de assuntos (FUJITA; SANTOS; ALVES, 2018).

O principal objetivo da linguagem de indexação é constituir um sistema de informação, como os catálogos, padronizados terminologicamente, através do controle de vocabulário. Considera-se significativo o controle de vocabulário, pois "contribui com a seleção, depuração, formalização e normalização da terminologia, incluindo, o estabelecimento recíproco entre os termos, considerando critérios semânticos, linguísticos e disciplinares" (BARITĖ, 2011, p. 127). Com isso, percebe-se que "estabelecimento recíproco entre os termos" faz com que haja compatibilidade entre termos utilizados na entrada e na saída do sistema de informação. As linguagens de indexação são regidas pela capacidade de compatibilizar a linguagem utilizada pelos usuários locais e de outras instituições, além de servirem como instrumento de representação da indexação realizada pelos indexadores no momento do tratamento temático (FUJITA; GIL LEIVA, 2010).

Tendo em vista o papel da linguagem de indexação como agente que viabiliza o controle de vocabulário no sistema de informação nas bibliotecas, afirma-se que são dois momentos que a linguagem pode ser utilizada: no processo de indexação, especificamente na etapa de tradução dos conceitos em uma linguagem utilizada no contexto organizacional da instituição, e no momento da busca pelo usuário em sua demanda por informação. Mediante esses dois pontos cruciais presentes no cotidiano das bibliotecas se faz necessário o uso da linguagem de indexação para a eficácia do sistema.

Segundo Guimarães (2009), por meio da indexação as bibliotecas, especialmente as especializadas, desempenham papel de apoio à pesquisa. Contudo, as bibliotecas universitárias também estão inseridas em um plano onde a pesquisa e as produções de conhecimento se manifestam como atividades inerentes às universidades.

Desse modo, percebe-se a função mediadora das linguagens de indexação entre diferentes tipos de linguagem. Configuram-se em lista de cabeçalho de assuntos, tesauros, anéis de sinônimos e sistemas de classificação, e diferenciam-se pela sua complexidade estrutural. Todavia, são 
dois fatores que constituem as linguagens de indexação: o vocabulário e a sintaxe. O vocabulário representa a lista de termos padronizados relacionados pela instituição para o tratamento de seus documentos, e a sintaxe que se configura nas relações existentes entre os termos presentes, ou seja, corresponde às regras de combinação de termos para representar o conteúdo temático dos documentos, por exemplo, apresenta regras ao uso de termos de indexação (PINTO, 1985).

O principal determinante da linguagem de indexação é seu fator de organização e mediação. Não é suficiente reunir expressões dos documentos sem que se faça haver um sentido próprio da particularidade do sistema de informação (LARA, 2004).

As linguagens de indexação, são construídas visando o controle de vocabulário e contribui para a representação e recuperação da informação. Portanto, observa-se o papel fundamental das discussões sobre as linguagens de indexação, a política de indexação que serve de amparo para a tomada de decisão até mesmo na construção de uma linguagem própria. Além disso, segundo Redigolo (2014) o âmbito de tratamento temático "mostra-se carente de instrumentos atualizados, como por exemplo, vocabulários controlados, políticas de indexação e também normalizações para indexação de conteúdo".

A política de indexação é uma ferramenta de trabalho do bibliotecário que auxilia para que o processo de indexação seja realizado de forma objetiva e consistente. É na política de indexação que são definidos fatores importantes e decisivos que interferem no resultado de um sistema de recuperação, como: cobertura de assuntos, seleção e aquisição dos documentos-fonte e os processos de indexação (como os critérios de especificidade e exaustividade, a escolha da linguagem e capacidade de revocação e precisão do sistema (CARNEIRO, 1985).

A linguagem de indexação é uma variável determinante que representa toda a política de indexação. É o fator determinante para que o indexador utilize os termos mais adequados ao representar o assunto de um documento, além de orientar o pesquisador/usuário na escolha dos termos correspondentes ao assunto por ele procurado (CARNEIRO, 1985). A escolha da linguagem é 
destacada por Rubi e Fujita (2006) pela sua importância, pois afeta o desempenho do sistema de recuperação de informação, na estratégia de busca (expressão que o usuário busca no sistema) e na indexação (estabelece a precisão com que o indexador pode descrever o assunto do documento).

Considerando as discussões teóricas apresentadas a respeito das linguagens de indexação no âmbito da organização da informação e abordando a relação da política de indexação nesse âmbito, o próximo item dedica-se a abordagem metodológica utilizada nessa pesquisa.

\section{METODOLOGIA}

Essa pesquisa de natureza exploratória, utilizou como ferramenta de coleta de dados o questionário, tendo em vista a capacidade de reunir informações de diversas instituições para o estudo analítico proposto.

O questionário aplicado é semelhante ao utilizado em pesquisas anteriores (CRUZ, 2017; FUJITA et al., 2019). Contudo, diante da trajetória das pesquisas realizadas e dos objetivos traçados em cada uma, o questionário passou por modificações.

O questionário aplicado é composto de quatro categorias: "Identificação", "Indexação na biblioteca", "Linguagem de indexação" e "Linguagem de Indexação e Política de Indexação". Estas obedecem a uma ordem sistemática para facilitar também para os respondentes. As questões do questionário estão relacionadas no Quadro 1, na qual apresentam-se as categorias de análise.

Em sequência, para enviar o questionário às demais regiões do território nacional, foi estabelecido contato com a Federação Brasileira de Associações de Bibliotecários (FEBAB) que ofereceu apoio a essa pesquisa e submeteu 0 questionário para a lista de bibliotecários da Comissão Brasileira de Bibliotecas Universitárias. Foram 1.181 bibliotecários que receberam o questionário, com 32 respostas obtidas por meio da Federação.

Para atingir maior número de bibliotecas respondentes, optou-se por utilizar uma base de dados online, disponibilizada pelo Ministério de Educação (MEC), o e-MEC. Essa base reúne informações sobre Instituições de Ensino Superior (IES) e cursos de graduação. De acordo com a descrição do site, o e- 
MEC é uma "base de dados oficial e única de informações relativas às Instituições de Educação Superior - IES e cursos de graduação do Sistema Federal de Ensino" (BRASIL, 2018).

$A$ base de dados e-MEC disponibiliza as informações referentes às instituições de ensino superior e não sobre bibliotecas. Sendo assim, houve a necessidade de entrar no site de cada universidade e pesquisar pelos dados das bibliotecas. Muitas bibliotecas não apresentavam informações para contato e foram desconsideradas. No final, reuniu-se 46 questionários respondidos, no qual todas as regiões brasileiras participaram: Norte - 6 bibliotecas; Nordeste 8; Centro-oeste - 2; Sudeste - 19; Sul - 13.

A região que mais teve retorno dos questionários foi a região Sudeste e Sul por apresentarem maior quantidade de universidades. Em seguida 0 Nordeste, Norte e o Centro-oeste que menos apresentou respostas.

\section{APRESENTAÇÃO E DISCUSSÃO DOS RESULTADOS}

A partir das quarenta e seis respostas obtidas pelo questionário e dos objetivos traçados inicialmente, foram elaboradas cinco categorias de análise e a última delas apresenta uma subcategoria: 1) Aspectos estruturais; 2) Aspectos de controle de vocabulário na biblioteca universitária; 3) Aprimoramentos quanto à aplicação das linguagens de indexação; 4) Manual de política de indexação; 4.1) Aspectos de controle de vocabulário na política de indexação.

No Quadro 1, as categorias de análise foram elaboradas buscando viabilizar o estudo dos dados, orientou-se a partir do objetivo de pesquisa e das próprias respostas obtidas no questionário.

Quadro 1 - Categorias de análise articuladas com as questões do questionário

\section{Categoria de análise no 1 - Aspectos estruturais}

3. Número de profissionais dedicados a tarefas de indexação.

4. Quais são as áreas de assunto que a coleção cobre?

5. A biblioteca está integrada a uma Rede ou Sistema de Bibliotecas? 5.1 Qual Rede ou Sistema?

6. Faz parte de catálogo coletivo?

6.1 Se faz parte de catálogo coletivo, indique as instituições cooperantes com as quais compartilha registros. 


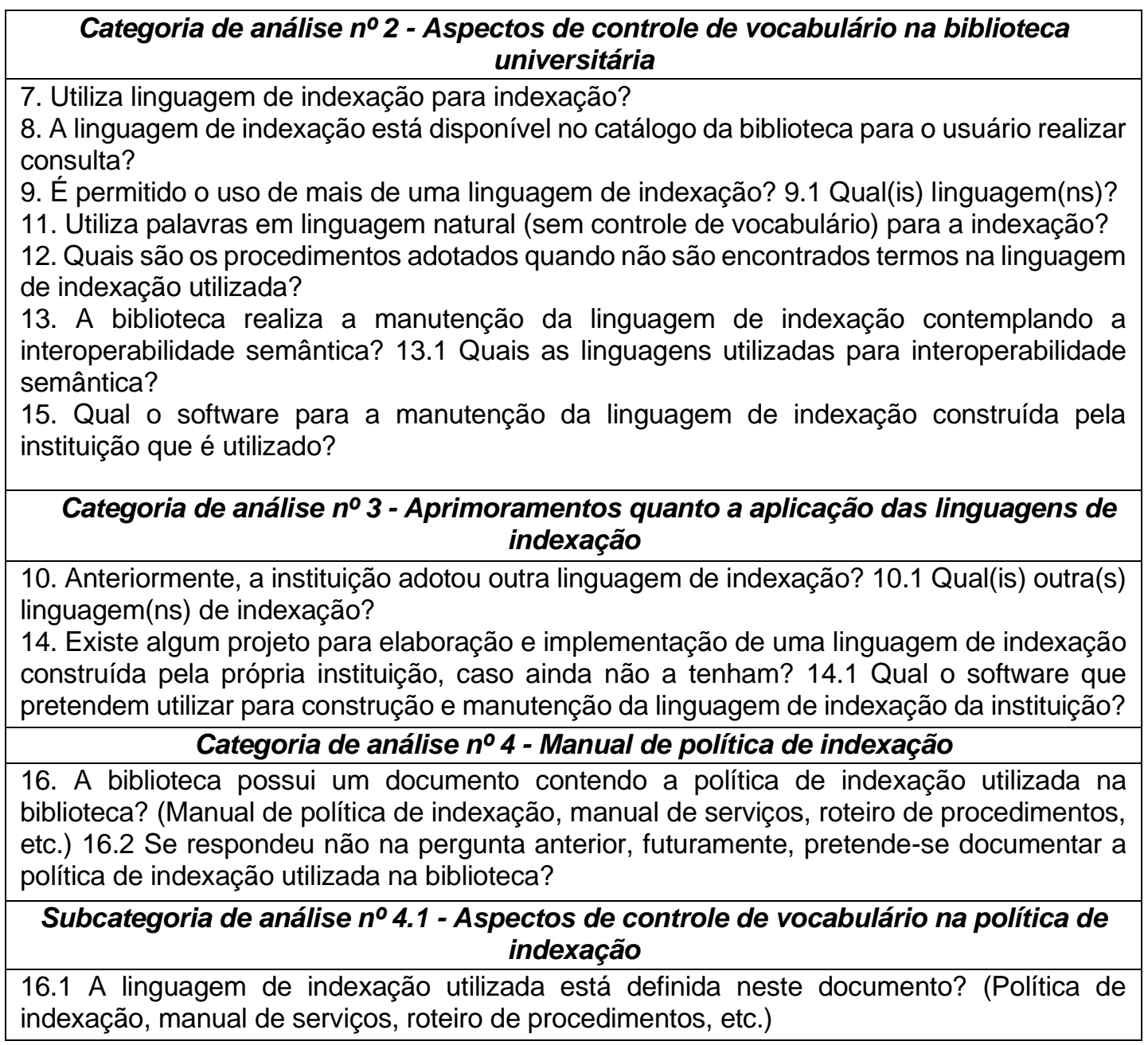

Fonte: Cruz (2019).

Ressalta-se que cada categoria de análise conta com a descrição, os objetivos traçados e também das subcategorias quando apresentadas.

\section{CATEGORIA DE ANÁLISE 1: ASPECTOS ESTRUTURAIS}

Descrição e objetivos da categoria: Buscando familiarização com a realidade da prática de indexação das bibliotecas foram examinados o número de profissionais dedicados à tarefa de indexação, além de buscar conhecer as áreas de assuntos que a coleção abrange, a integração em uma rede ou sistemas de bibliotecas e a participação de catálogo coletivo.

\section{$>$ Número de profissionais dedicados à indexação (Questão 3)}

A indexação dos documentos faz parte das principais atividades realizadas em uma biblioteca, sendo fundamental que haja pessoas capacitadas para desempenhar a função de indexação. Dessa forma, foi visto que apenas 
uma biblioteca não soube informar o número de indexadores, nas demais, todas informaram. No Quadro 2, diante de várias respostas obtidas, demonstra-se a quantidade de bibliotecas em relação à quantidade de indexadores.

Quadro 2 - Relação de bibliotecas e indexador

\begin{tabular}{|l|l|}
\hline \multicolumn{1}{|c|}{ Quantidade de bibliotecas } & \multicolumn{1}{c|}{ Quantidade de indexadores } \\
\hline 7 bibliotecas & 1 indexador \\
\hline 14 bibliotecas & 2 indexadores \\
\hline 8 bibliotecas & 3 indexadores \\
\hline 7 bibliotecas & 4 indexadores \\
\hline 1 bibliotecas & 5 indexadores \\
\hline 4 bibliotecas & 6 indexadores \\
\hline 1 bibliotecas & 7 indexadores \\
\hline 2 bibliotecas & 12 indexadores \\
\hline 1 biblioteca & 15 indexadores \\
\hline
\end{tabular}

Fonte: Cruz (2019).

Estima-se que os respondentes que apresentam doze e quinze indexadores referiram-se ao número de indexadores da rede, por ser um número alto de bibliotecários em uma única unidade. Segundo Santa Anna, Calmon e Campos (2016, p. 62) vários fatores podem determinar o tratamento da informação, como as proporcionadas "pela subjetividade, pela experiência e pelo conhecimento prévio imbuídos na pessoa do catalogador/indexador/classificador". Desse modo, tendo em vista a quantidade de indexadores, considera-se imprescindível o uso de ferramentas e métodos que viabilizem a padronização dos procedimentos para criar consistência nas decisões tomadas, em conformidade com a realidade da biblioteca e/ou rede.

\section{Cobertura de áreas de assunto da coleção (Questão 4)}

Como a questão apresentava-se de forma "aberta", permitiu-se que os bibliotecários respondessem de forma textual. Optou-se por relacionar as respostas em quatro grupos gerais para viabilizar a tabulação e a visualização das respostas obtidas: $37 \%$ acervo com todas as áreas de assunto; $30 \%$ acervo com uma área de assunto especializada; $20 \%$ acervo com até quatro áreas especializadas de assuntos; e $13 \%$ acervo com mais de quatro áreas de assuntos. 
Consultou-se a tabela de assuntos disponibilizada pelo Conselho Nacional de Desenvolvimento Científico e Tecnológico (CNPQ) para elaborar os quatro grupos gerais acima.

Ressalta-se que quatro das dezessete bibliotecas que responderam pela abrangência de todas as áreas de conhecimento consideraram a rede em que estão inseridas. As demais informaram abranger áreas multidisciplinares, todas as áreas ou todas relacionadas pelo CNPQ. O segundo maior grupo que contemplou uma área de assunto especializada resultou em 14 bibliotecas das 46 pesquisadas (30\%). Nessas bibliotecas, há o interesse de acompanhar o curso disponibilizado pela faculdade local nas quais estão inseridas, como área da saúde, ciências jurídicas, ciências sociais, etc. Nessa mesma lógica, seguem os grupos que abrangem acervo com até quatro áreas especializadas de assuntos, sendo nove das 46 bibliotecas analisadas (20\%) e com mais de quatro áreas especializadas de assuntos, seis bibliotecas (13\%). Diante de um cenário de crescimentos exponenciais de universidades particulares pelo Brasil, a quantidade de cursos oferecidos por unidade também vem acompanhando esse crescimento. Nessa realidade, as bibliotecas universitárias seguem essa alta demanda de materiais bibliográficos para atender os cursos disponibilizados. Por isso, os acervos tendem a conter uma grande quantidade de assuntos.

\section{Participação em rede ou sistema de bibliotecas (Questão 5)}

Identificou-se que quarenta e uma das quarenta e seis bibliotecas fazem parte de uma rede ou sistema de bibliotecas, sendo que cinco delas não. A rede é um sistema que é "alimentado" por dados inseridos pelos bibliotecários. Por conseguinte, é importante que haja comunicação entre os bibliotecários, treinamentos em conjunto para a capacitação e, além disso, ferramentas selecionadas e/ou desenvolvidas para que possam contribuir com o tratamento da informação.

Quando o bibliotecário é responsável pelo tratamento técnico, os sistemas utilizados para tal função disponibilizam funções facilitadoras, como por exemplo, gerar automaticamente o código do autor presente no número de chamada, a conformidade no registro de autoridades para que não haja diferentes pontos de acesso de uma mesma entidade, ou mesmo o uso de 
distintas linguagens de indexação para representar o conteúdo dos documentos. Como se pode observar são várias as funções de um sistema de bibliotecas que dependem de uma compatibilidade de procedimentos dos bibliotecários. Por essa razão, buscou-se identificar quais as bibliotecas universitárias fazem parte de uma rede ou sistema.

Os sistemas de bibliotecas verificados foram:

- Sistema de Bibliotecas e Informação da Universidade Federal do Rio de Janeiro (UFRJ) - 5 bibliotecas

- Sistema Integrado de Bibliotecas da Universidade de São Paulo (SIBiUSP)- 4

- Sistema de Bibliotecas da Universidade Federal do Ceará (UFC) - 3

- Databiblio (BIBLIODATA) - 3

- Rede do Catálogo Coletivo Nacional - 2

- Núcleo de Biblioteca e Documentação da Universidade de Pernambuco (NBID) - 2

- Sistema de Bibliotecas da Universidade Federal do Sul da Bahia (UFSB) 2

- Sistema de Bibliotecas da Universidade Federal do Rio Grande do Sul (SBUFRGS) - 2

- Sistema de Bibliotecas da Universidade Federal do Rio Grande (FURG) 2

- Rede de Bibliotecas Lassalistas (REDEBILA)

- Rede de Bibliotecas Universidade de Passo Fundo (UPF)

- Rede Biblioteca Virtual de Saúde (BVS)

- Sistema Integrado de Bibliotecas da Universidade de Taubaté (SIBIUNITAU)

- Sistema de Bibliotecas da Universidade Federal do Pará (UFPA)

- Sistema de Bibliotecas da Universidade Federal do Tocantins Biblioteca Digital de Teses e Dissertações (BDTD)

Foram citados também o SOPHIA (2 respostas) e o Pergamum (12 respostas), no entanto não são sistemas de bibliotecas e sim softwares de gestão de bibliotecas. 
$\geq$ Participação em catálogo coletivo para compartilhamento de registros (Questão 6)

O compartilhamento de registros entre catálogos foi praticamente dividido pela metade das respostas, na qual 24 bibliotecas negam fazer parte de catálogo coletivo (52,2\%) e outras 22 compartilham registros (47,8\%). Em seguida, verificaram-se as instituições cooperantes com as quais são compartilhados os registros. As instituições cooperantes citadas mais de uma vez, foram:

- BIBLIODATA - 3 bibliotecas

- Universidade Federal do Ceará - 3

- Universidade de São Paulo (USP) - 3

- Catálogo Coletivo Nacional - 3

- Universidade Federal do Rio de Janeiro - 2

Também foram citados: Literatura Latino-americana e do Caribe em Ciências da Saúde (LILACS), os Seriados em Ciências da Saúde (SeCS), BIREME, Universidade de Campinas (UNICAMP), Universidade Federal do Paraná (UFPR), Pontifícia Universidade Católica do Paraná (PUCPR) e Universidade Federal do Rio Grande do Sul (UFRGS). Novamente foi citado o Pergamum (7 bibliotecas) e o SOPHIA biblioteca, estima-se que alguma dessas respostas decorreram da questão anterior sobre catálogo coletivo da instituição, na qual são compartilhados os registros com outras unidades da própria rede, como a Universidade de Taubaté e a Universidade de Pernambuco, por exemplo.

\section{CATEGORIA DE ANÁLISE 2: ASPECTOS DE CONTROLE DE VOCABULÁRIO NAS BIBLIOTECAS UNIVERSITÁRIAS}

Descrição e objetivos da categoria: Essa categoria é a que apresenta maior quantidade de questões, ao todo são sete centrais, buscando verificar como as bibliotecas compreendem o estágio de tradução dos conceitos pela linguagem de indexação. Os aspectos de controle de vocabulário reunidos nesta categoria são relacionados ao uso de linguagens de indexação.

\section{$>$ Uso da linguagem de indexação (Questão 7)}

$O$ uso da linguagem de indexação faz parte dos procedimentos adotados no processo de indexação, é a etapa de tradução dos conceitos visando o 
controle de vocabulário (SOUSA; FUJITA, 2014; MACULAN; LIMA, 2011). A maioria das bibliotecas declara utilizar linguagem de indexação no processo de indexação de assuntos. São 39 bibliotecas que utilizam e sete que não fazem uso. Percebe-se que com esse resultado os bibliotecários, em sua maioria, compreendem a necessidade do uso da linguagem de indexação em uma biblioteca universitária, onde a busca e recuperação da informação são imprescindíveis para gerar a base de pesquisa dos discentes e docentes da universidade, contribuindo para o engrandecimento da instituição como um centro de pesquisa e geração de conhecimento.

Linguagem de indexacão disponível no catálogo da biblioteca para consulta do usuário (Questão 8)

Verificou-se que vinte bibliotecas não disponibilizam a linguagem em seus catálogos. Porém, praticamente a metade das bibliotecas, dezoito delas, afirmam dispor desse recurso. Entende-se com esse resultado que as bibliotecas estão com foco na participação do usuário e em sua capacitação em realizar a busca com maior precisão na escolha dos termos.

Ao disponibilizar a linguagem de indexação ao usuário permitimos a ele maior autonomia de pesquisa, uma vez que o processo de busca se tornará mais eficiente e os resultados mais precisos. Isso só seria possível com a combinação do processo de indexação com linguagem(ns) de indexação padronizada pela instituição mais a disponibilidade dessa ferramenta de vocabulário para o usuário. As linguagens de indexação fazem um processo de mediação entre a linguagem do usuário, a linguagem do sistema e as linguagens consultadas pelo indexador em outros sistemas de bibliotecas. Posto isso, é visto a importância de informar sobre o papel desse instrumento que é utilizado pelo bibliotecário e deve ser parte do processo de busca do usuário. Dessa forma, há um alinhamento no método de representação do conteúdo dos documentos com a forma de recuperação da informação.

\section{Uso de mais de uma linguagem de indexacão (Questão 9)}

Nesta questão, foi verificado que vinte e cinco bibliotecas utilizam mais de uma linguagem de indexação (54,3\%), enquanto vinte e uma das quarenta e seis bibliotecas não utilizam (45,7\%). Quando a instituição não dispõe de uma 
linguagem de indexação construída especificamente para suas necessidades, as bibliotecas universitárias, por abrangerem várias áreas do conhecimento, precisam recorrer a diferentes vocabulários para o tratamento da informação. Isso pode dificultar o processo de indexação ao levar mais tempo de procedimento e ocasionar a combinação do uso de uma linguagem de indexação com linguagem natural.

Anteriormente, na questão 7 , verificou-se que trinta e nove bibliotecas utilizavam linguagem de indexação. Contudo, nesta questão que buscava saber quais linguagens de indexação eram utilizadas pelas bibliotecas, trinta e quatro responderam. Nove das trinta e quatro bibliotecas que responderam à questão, sendo a maior parcela das bibliotecas (26\%), não especificaram a linguagem de indexação utilizada. Foram obtidas respostas vagas como: "vocabulário controlado", "linguagem compartilhada pela rede", "cabeçalho de assuntos, tesauros, esquemas de classificação", "vocabulários que cobrem temáticas de trabalhos multidisciplinares". A segunda maior parcela, contando com seis bibliotecas $(23 \%)$, utilizam uma linguagem de indexação. Foram citadas as linguagens:

- Descritores em Ciências da Saúde (DeCs)

- Vocabulário controlado da USP

- Library of Congress Subject Headings (LCSH)

- Terminologia de assuntos da Biblioteca Nacional Brasileira.

\section{Uso de palavras em linguagem natural (Questão 11)}

Verificou-se que são vinte e quatro bibliotecas $(52,2 \%)$ que utilizam apenas linguagem de indexação, ao passo que vinte e duas $(47,8 \%)$ utilizam termos livres, sem controle de vocabulário. Cardoso Filho e Santos (2012) consideram que o emprego da linguagem natural dificulta a recuperação da informação. Os autores ressaltam que há uma variedade de termos que se pode utilizar para descrever um documento. Contudo, ao utilizar uma linguagem de indexação o indexador pode optar por um termo que seja autorizado, além de fazer com que as remissivas indiquem o termo permitido.

A ISO (25964) especifica que faz parte do processo de indexação o uso de termos de indexação para a informação ser recuperada. Dessa forma, faz 
parte da indexação o uso de termos controlados para descrição do conteúdo dos documentos. Como visto a seguir, há bibliotecas que utilizam a combinação de linguagem natural com linguagem de indexação, outras apenas linguagem natural. A combinação da linguagem natural com uma linguagem de indexação entra em contradição com a função de padronização e consistência da indexação. Pressupõe que essa combinação seja feita quando o indexador não encontra o termo desejado na linguagem de indexação utilizada.

\section{Procedimentos quando não são encontrados os termos na} linguagem de indexacão utilizada (Questão 12)

Ao realizar a indexação, pode acontecer do bibliotecário não encontrar o termo específico requerido para a descrição do material trabalhado. À vista disso, perguntou-se a respeito dos procedimentos adotados quando o bibliotecário se encontra nessa situação. É importante que essa decisão seja inserida no manual de política de indexação para que o bibliotecário não fique sem orientações. Em decorrência de várias respostas obtidas, foram elaborados grupos para relacionar as respostas e facilitar a análise. Foram quatro grupos de resultados: a) Pesquisa em outras linguagens de indexação (13); b) Inclusão do termo mediante análise em grupos (6); c) Emprego da linguagem natural (18); d) Atribuição de termos semelhantes ou mais gerais (7). Duas respostas não foram contabilizadas por não explicarem os procedimentos utilizados.

a) Pesquisa em outras linguagens de indexação: são treze bibliotecas que adotam a prática de pesquisar em outras linguagens de indexação para validarem suas tomadas de decisões. Não passam por uma análise em grupo ou com o consentimento de outros bibliotecários que utilizam do sistema. A consulta em outras linguagens de indexação pode causar diferenciação nos termos já utilizados no sistema da biblioteca, em todo caso, quando há um documento novo a ser indexado, com um assunto específico ou inédito, é relevante realizar essa pesquisa em outras linguagens. Como verificado anteriormente, as linguagens de indexação têm a responsabilidade no controle de polissemias, homônimos, sinônimos e ambiguidade (SVENONIUS, 2000). Essa prática garante que essas imprecisões na indexação não aconteçam.

b) Inclusão do termo mediante análise em grupos: verificou-se que seis 
bibliotecas fazem a inclusão dos termos mediante análises em grupos. Diante dessa prática, pode-se discutir com pessoas que possuem experiência com a indexação do sistema da biblioteca em questão e fazer a melhor escolha para descrever os documentos, proporcionando consistência e respaldo das decisões tomadas. Assim como dito anteriormente, considera-se fundamental realizar pesquisa em outras linguagens de indexação e incluir a discussão em grupo próprio responsável por cuidar desses assuntos. Essas duas ações em conjunto permitem que os procedimentos sejam consistentes, assim como os termos utilizados. Além disso, uma ferramenta fundamental para nortear o indexador é o manual de política de indexação que regulamenta os processos de indexação, delimita a filosofia da instituição e antecipa soluções para situações como esta levantada nessa questão do questionário.

c) Emprego da linguagem natural: o maior grupo de respostas, de dezoito bibliotecas, foi que respondeu inserir o termo em linguagem natural. Percebe-se que muitos acreditam que a decisão do bibliotecário mediante a leitura do material e consulta das palavras-chave, por exemplo, já basta para a criação do termo. Essa pode até ser uma decisão recorrente, mas deve ser analisada para evitar a criação de termos inconsistentes no sistema da biblioteca. O ideal é apresentar a sugestão de adoção do termo para grupos de gestão, caso não encontrado na(s) linguagem(ns) de indexação utilizadas e constatar se é válido ou não incluí-lo.

d) Atribuição de termos semelhantes ou mais gerais: obtiveram-se sete respostas. Considera-se que seja uma decisão coerente desde que seja documentado em um manual de indexação. Isso cria um padrão de procedimentos a serem adotados em relação à especificidade da indexação. Contudo, ressalta-se que o usuário precisa acompanhar esse tipo de procedimento no momento da busca no catálogo da biblioteca, pois este não estaria ciente dessa forma de representação. Novamente, destaca-se a importância de disponibilizar a linguagem de indexação para o usuário.

Manutencão da linguagem de indexação contemplando a interoperabilidade semântica (Questão 13)

A interoperabilidade semântica é um recurso de construção de linguagens 
de indexação que utiliza a fusão com outras linguagens existentes. Em outras palavras, a interoperabilidade semântica é uma capacidade de sistemas autônomos de trocar ou compartilhar conteúdos conceituais, por meio de padrões semelhantes e de protocolos utilizados (MOURA, 2009; BOCCATTO; TORQUETTI, 2012).

Por conseguinte, seis das quarenta e seis bibliotecas afirmaram fazer a manutenção dessa forma. Assim, questionou-se às bibliotecas para verificar as linguagens de indexação utilizadas. Não foram consideradas três respostas, pois não responderam à pergunta referida. Uma biblioteca mencionou utilizar linguagem natural, Library of Congress, Terminologia da Biblioteca Nacional brasileira e a Rede Pergamum. Ressalta-se que a linguagem natural e a Rede Pergamum não são linguagens de indexação por não promoverem controle de vocabulário e por ser um software de gestão de bibliotecas, respectivamente.

Dito isso, foram citadas as linguagens de indexação: Medical Subject Headings (MeSH), Systematized Nomenclature of Medicine - ClinicalTerms (SNOMED CT), Terminologia da Biblioteca Nacional brasileira e Vocabulário da USP.

Software de construcão e manutenção da linguagem de indexação

\section{(Questão 15)}

Essa pergunta foi direcionada às bibliotecas que já construíram e implementaram sua linguagem de indexação. Apesar de sete bibliotecas expressarem já possuir linguagem construída pela própria instituição, foram seis que responderam sobre os softwares de gestão de linguagem. Desconsiderouse duas respostas por não citarem nenhum software de linguagens de indexação e outras quatro bibliotecas relataram que utilizam ou irão migrar para $o$ TemaTres.

Quando a instituição busca aprimorar o âmbito do tratamento temático da informação ao desenvolver uma linguagem de indexação que represente a filosofia da instituição, é fundamental analisar softwares para seu desenvolvimento, além dessa atividade ser amparada por normas e pela própria política de indexação da instituição. Os softwares de construção de linguagem de indexação possibilitam que seja desenvolvida uma estrutura desejada, como 
tesauros, por exemplo, em cadeia hierarquizada. Entretanto, é sabido que as ciências estão em constante evolução diante das novas descobertas e estudos. Por esse motivo, a linguagem de indexação está em constante crescimento e adaptação de seus conceitos. Sobre isso, Campos et al. (2006) reforça a ideia da necessidade do uso de softwares para a construção de vocabulários, devido às facilidades de criação, manipulação, atualização e apresentação dos termos definidos e suas relações.

\section{CATEGORIA DE ANÁLISE 3: APRIMORAMENTOS QUANTO À APLICACÃO DAS LINGUAGENS DE INDEXACÃO}

Descrição e objetivos da categoria: Com o objetivo de verificar mudanças no cenário no tratamento temático da informação, as seguintes respostas foram analisadas:

\section{$\geq$ Linguagens de indexacão anteriormente utilizadas (Questão 10)}

A mudança de vocabulários utilizados não significa que a linguagem de indexação é ultrapassada, muitas vezes a instituição opta por desenvolver a própria linguagem de indexação ou utilizam outras linguagens de indexação por representar melhor os assuntos que a biblioteca possui em seu acervo. Podem ser vários os motivos para optarem por essa mudança.

Objetivando compreender um pouco mais o universo das bibliotecas pesquisadas em que se inserem as linguagens de indexação, constatou-se que trinta e seis delas $(78,3 \%)$ relatam nunca terem utilizado outra linguagem de indexação no passado, enquanto dez bibliotecas afirmam já ter aplicado outras linguagens. Em sua maioria, foi citada a linguagem natural que não representa uma linguagem de indexação e sim termos livres empregados pelos bibliotecários. Também foram citados: Spines, Bibliodata da Faculdade Getúlio Vargas (FGV), cabeçalhos extraídos da CDD, National Library of Medicine (NLM), Medical Subject Headings (MeSH) e terminologia de assuntos da Biblioteca Nacional brasileira. Uma biblioteca em especial, relembrou que antigamente as bibliotecas do Sistema possuíam listas de termos locais, listas de cabeçalho de assuntos, e com a informatização do sistema e a criação do Catálogo Bibliográfico da USP (Dedalus), houve necessidade de padronizar a 
indexação, criando-se assim o vocabulário próprio da instituição.

\section{Projeto para elaboracão e implementacão de uma linguagem de}

\section{indexacão (Questões 14 e 14.1)}

A construção de uma linguagem de indexação própria da instituição permite que seja realizado um trabalho com uma equipe técnica de profissionais, que elabore uma estrutura capaz de suprir as necessidades de representação da informação, coerente com a realidade da biblioteca ou da rede.

A maioria das bibliotecas não possuem projetos para a elaboração e implementação de uma linguagem construída pela própria instituição. Isso porque muitas já consultam e estão habituadas a adoção de uma determinada linguagem de indexação. Em todo caso, é importante que seja avaliado pela biblioteca se é interessante elaborar uma linguagem de indexação, assim como se verificou que sete bibliotecas $(15,2 \%)$ já estão com planos para essa tarefa. Pode-se observar também seis bibliotecas (13\%) já apresentam suas linguagens de indexação.

Buscando saber um pouco mais das bibliotecas que objetivam construir uma linguagem de indexação, foi perguntado, na questão 14.1, qual software de construção e manutenção de linguagem pretendem utilizar. Três bibliotecas citaram o ALEPH e o ARGO que são sistemas de administração de bibliotecas. Para a construção de uma linguagem é necessário um software específico e, principalmente, para a sua manutenção com inserção e remoção de termos, por exemplo. As outras quatro bibliotecas informaram que os projetos estão em sua fase de elaboração e ainda não foi decidida essa questão.

\section{CATEGORIA DE ANÁLISE 4: MANUAL DE POLÍTICA DE INDEXACÃO}

Descrição e objetivos da categoria: Esta é a última categoria do questionário apresentado às bibliotecas universitárias. Assim como nos estudos teóricos realizados, chegou-se à conclusão que a linguagem de indexação deve estar representada na política de indexação para que haja um padrão nos procedimentos a serem adotados (GIL LEIVA, 2008; FUJITA, 2016). Nessa categoria, busca-se verificar questões a respeito da presença de manual de política de indexação nas bibliotecas universitárias. Apresenta também uma 
subcategoria de análise sobre os aspectos de controle de vocabulário na política de indexação.

\section{$>$ Documento contendo a política de indexação (Questão 16)}

O documento contendo a política de indexação pode ser um manual de política de indexação, manual de serviços, roteiro de procedimentos, etc. Independente da nomenclatura houve a intenção de saber se as bibliotecas possuem um documento dos procedimentos realizados no processo de indexação.

São vinte e cinco bibliotecas (54,3\%), de quarenta e seis estudadas, que apresentam uma política de indexação documentada. Apesar de ser o maior grupo de respostas, vinte e uma $(45,7 \%)$ não possuem esse documento. Sobre isso, de acordo com Cleveland e Cleveland (2013), as decisões do indexador devem ser guiadas pela política de indexação, ela é a base que conduz os procedimentos adotados. Deste modo, os aspectos de controle de vocabulário devem estar presentes na política de indexação e por esse motivo muitas respostas sobre as linguagens de indexação mostraram procedimentos não normalizados e que podem gerar inconsistência no resultado final de busca.

\section{$\geq$ Intenção de documentar a política de indexação (Questão 16.2)}

Para as bibliotecas que responderam não dispor de uma política de indexação, foi perguntado se há interesse em, futuramente, documentarem seus procedimentos adotados na indexação. Das vinte e uma bibliotecas que responderam não possuir esse documento, dezessete pretendem elaborar um manual de política de indexação (81\%), enquanto quatro não (19\%). Quantitativamente, o resultado mostrou-se favorável à implantação de melhorias na formalização dos processos da indexação. A documentação da política de indexação revela a biblioteca como uma organização e seus procedimentos norteados por uma filosofia institucional (RUBI, 2004).

\section{Subcategoria de análise 4.1: Aspectos de controle de vocabulário na}

\section{política de indexação}

Descrição e objetivos da subcategoria: Busca-se verificar sobre os manuais de política de indexação, especificando as bibliotecas que utilizam um 
documento contendo a política de indexação e ferramentas de controle de vocabulário, tais como as linguagens de indexação.

$\geq$ Definição da linguagem de indexação no documento referente à política de indexação (Questão 16.1)

A linguagem de indexação é uma escolha feita com base nas necessidades do sistema de informação. É uma variável fundamental definida na política de indexação (RUBI; FUJITA, 2006). Em razão disso, foi perguntado se as bibliotecas que possuem política de indexação formalizada apresentam a linguagem de indexação nela definida. Constatou-se que vinte e duas das vinte e cinco bibliotecas (88\%), especificam informações e particularidades sobre controle de vocabulário adotado no documento de registro da política de indexação.

\section{CONSIDERAÇÕES FINAIS}

A respeito da aplicação das linguagens de indexação em bibliotecas universitárias, foi possível verificar que em sua maioria fazem uso da ferramenta para o tratamento de seus documentos. Contudo, considera-se necessário precaução nos procedimentos adotados quando não são encontrados termos na linguagem de indexação utilizada, a fim de que não haja inconsistência nas tomadas de decisões, pois iria refletir negativamente na organização e recuperação da informação.

Tendo em vista os procedimentos adotados quando não são encontrados os termos na linguagem de indexação utilizada, o uso de linguagem natural e o uso de várias linguagens de indexação, considera-se possível que as bibliotecas encontrem benefícios em elaborar uma linguagem de indexação própria e condizente com a filosofia institucional a qual pertencem, como verificou-se que sete das quarenta e seis bibliotecas já apresentam projetos para isso. Caso não seja possível a elaboração de uma linguagem de indexação, estabelecer em uma política de indexação as linguagens utilizadas referentes a determinados tipos de assuntos. Porém, cabe ressaltar que isso dificultaria a estratégia de busca do usuário. 
A disponibilização da linguagem de indexação para o usuário pode gerar familiaridade com os termos utilizados no tratamento temático e contribuir com resultados positivos na recuperação da informação, além de, possibilitar o enriquecimento da linguagem de indexação com a inclusão de novos termos. Contudo, mais da metade não disponibiliza a linguagem ao usuário o que pode causar imprecisão no momento da busca, por incompatibilidade entre as linguagens utilizadas, a do sistema e a do usuário. Em pesquisas futuras, seria apropriado verificar no catálogo das bibliotecas a maneira como a linguagem de indexação está disponível para a consulta do usuário.

\section{REFERÊNCIAS}

ALBRECHTSEN, $\mathrm{H}$. Subject analysis and indexing: from automated indexing to domain analysis. The Indexer, London, v. 18, n. 4, p. 219-224, 1993.

Disponível em: http://www.theindexer.org/files/18-4/18-4_219.pdf. Acesso em: 11 mar. 2019.

BARITÈ, M. G. Sistemas de Organización del Conocimiento: uma tipologia actualizada. Informação \& Informação, Londrina, v. 16, n. 3, p. 122-139, 2011. Disponível em:

http://www.uel.br/revistas/uel/index.php/informacao/article/view/9952. Acesso em: 23 jul. 2019.

BOCCATO, V. R. C.; TORQUETTI, M. C. Interoperabilidade entre linguagens de indexação como recurso de construção de instrumento de representação temática de clippings de coordenadorias de comunicação social em ambientes universitários: uma proposta metodológica. Informação \& Informação, Londrina, v. 17, n. 3, p. 76-101, set./dez. 2012. Disponível em: http://www.uel.br/revistas/uel/index.php/informacao/article/view/10800. Acesso em: 15 ago. 2018.

BRASIL. Ministério da Educação. Portaria normativa no 40, de 12 de dezembro de 2007. Institui o e-MEC, sistema eletrônico de fluxo de trabalho e gerenciamento de informações relativas aos processos de regulação da educação superior no sistema federal de educação. Disponível em: http://portal.mec.gov.br/setec/arquivos/pdf_legislacao/superior/legisla_superior_ port40.pdf. Acesso em: 16 ago. 2017.

CAMPOS, M. L. A.; GOMES, H. E.; MARTINS, A. E.; CAMPOS, M. L. M.; CAMPOS, L. M.; SALES, L. F. Estudo comparativo de softwares de construção de tesauros. Perspectivas em Ciência da Informação, Belo Horizonte, v. 11 n. 1, p. 68-81, jan./abr. 2006. Disponível em: 
http://www.scielo.br/scielo.php?pid=S1413-

99362006000100006\&script=sci_abstract\&tIng=pt. Acesso em: 18 jan. 2018.

CARDOSO FILHO, J. C.; SANTOS, M. M. Processos e temas selecionados. In: ALVARES, L. (org.). Organização da informação e do conhecimento: conceitos, subsídios interdisciplinares e aplicações. São Paulo: B4 Editores, 2012. p. $185-223$.

CARNEIRO, M. V. Diretrizes para uma política de indexação. Revista da Escola de Biblioteconomia da UFMG, Belo Horizonte, v. 14, n. 2, p. 221-241, set. 1985.

CHOWHURY, G. G. Knowledge organization or information organization? A key component of knowledge management activities. In: INTERNATIONAL CONFERENCE ON DIGITAL LIBRARIES, 2004. Disponível em: https://pdfs.semanticscholar.org/6bf8/7feb19c6dd73da8a309c199e95920410f55 7.pdf. Acesso em: 01 abr. 2019.

CLEVELAND, D. B.; CLEVELAND, A. D. Introduction to indexing and abstracting. 4. ed. Santa Barbara, California: Libraries Unlimited, 2013.

CRUZ, M. C. A. Linguagem de indexação no contexto da política de indexação: estudo em bibliotecas universitárias. 2017. $61 \mathrm{f}$. Trabalho de Conclusão de Curso (Graduação em Biblioteconomia) - Faculdade de Filosofia e Ciências, Universidade Estadual Paulista, Marília, 2017.

CRUZ, M. C. A. Linguagens de indexação em bibliotecas universitárias: estudo analítico em território nacional. 2019. 82 p. Dissertação (Mestrado em Ciência da Informação) - Faculdade de Filosofia e Ciências, Universidade Estadual Paulista, Marília, 2019.

DIAS, E. W.; NAVES, M. M. L. Análise de assunto: teoria e prática. Brasília: Thesaurus, 2007.

FUJITA, M. S. L.; CRUZ, M. C. A.; PATRÍCIO, B. O. M.; RIO BRANCO, L. B. P. Linguagens de indexação em bibliotecas universitárias: estudo analítico.

Informação \& Informação, Londrina, v. 24, n. 1, p. 190-225, 2019. Disponível em: http://www.uel.br/revistas/uel/index.php/informacao/article/view/31771. Acesso em 01 fev. 2019.

FUJITA, M. S. L. A representação documentária no processo de indexação com o modelo de leitura documentária para textos científicos e livros: uma abordagem cognitiva com protocolo verbal. Ponto de Acesso, Salvador, v. 7, n. 1, p. 42-66, abr. 2013. Disponível em: www.pontodeacesso.ici.ufba.br. Acesso em: 30 ago. 2019.

FUJITA, M. S. L. Política de indexação para bibliotecas: funções e finalidades. In: FUJITA, M. S. L. (org.). Política de indexação para bibliotecas: 
elaboração, avaliação e implantação. Marília: Oficina Universitária; São Paulo: Cultura Acadêmica, 2016.

FUJITA, M. S. L.; GIL LEIVA, I. As linguagens de indexação em bibliotecas nacionais, arquivos e sistemas de informação na América-latina. In: SEMINÁRIO NACIONAL DE BIBLIOTECAS UNIVERSITÁRIAS, 16., SEMINÁRIO INTERNACIONAL DE BIBLIOTECAS DIGITAIS, 2., 2010, São Conrado. 2010. Anais [...]. São Conrado: Universidade Federal do Rio de Janeiro, 2010.

FUJITA, M. S. L.; SANTOS, L. B. P.; ALVES, R. V. ¿Son los lenguajes de indización y documentales sistemas de organización del conocimiento? Un análisis bardiano de la variación terminológica. Scire, Zaragoza, v. 24, n. 2, p. 23-34, jul. dez. 2018. Disponível em: https://www.ibersid.eu/ojs/index.php/scire/. Acesso em: 1 nov. 2018.

GIL LEIVA, I. Manual de indización: teoría y práctica. Gijón: Trea, 2008.

GUIMARÃES, J. A.C. Abordagens teóricas de tratamento temático da informação: catalogação de assunto, indexação e análise documental. Ibersid, Zaragoza, v. 3, p. 105117, 2009. Disponível em:

https://www.ibersid.eu/ojs/index.php/ibersid/article/view/3730. Acesso em: 5 fev. 2014

ISO 25964-1. Information and documentation: part 1: thesauri and interoperability with other vocabularies. Geneva: International Organization for Standardization, 2011.

LARA, M. L. G. Linguagem documentária e terminologia. Transinformação, Campinas, v. 16, n. 3, p. 231-240, set./dez., 2004.

MACULAN, B. C. M. S.; LIMA, G. A. B. O. modelo para análise conceitual de teses e dissertações com vistas à criação de taxonomia facetada. Informação \& Sociedade: Estudos, João Pessoa, v. 21, n. 3, p. 41-54, set./dez. 2011. Disponível em: http://periodicos.ufpb.br/ojs2/index.php/ies/article/view/9582. Acesso em: 23 jan. 2019.

MAI, J. E. Semiotics and indexing: an analysis of the subject indexing process. Journal of Documentation, London, v. 57, n. 5, set. 2001. Disponível em: http://jenserikmai.info/Papers/2001_Semiotics.pdf. Acesso em: 18 set. 2018.

MOURA, M. A. Informação, ferramentas ontológicas e redes sociais ad hoc: a interoperabilidade na construção de tesauros e ontologias. Informação \&

Sociedade: Estudos, João Pessoa, v. 19, n. 1, p. 59-73, jan./abr., 2009.

Disponível em: http://mamoura.eci.ufmg.br/wpcontent/uploads/2014/10/informacao-ferramentas-sociais-add-hoc.pdf. Acesso em: 13 out. 2018. 
PINTO, M. C. M. F. Análise e representação de assunto em sistemas de recuperação da informação: linguagens de indexação. Revista da Escola de Biblioteconomia da UFMG, Belo Horizonte, v. 14, n. 2, p. 169-186, set. 1985.

REDIGOLO, F. M. O processo de análise de assunto na catalogação de documentos: a perspectiva sociocognitiva do catalogador em contexto de biblioteca universitária. 2010. 176 f. Dissertação (Mestrado em Informação, Tecnologia e Conhecimento) - Faculdade de Filosofia e Ciências, Universidade Estadual Paulista, 2010. Disponível em: http://hdl.handle.net/11449/93668. Acesso em: 1 abr. 2019.

REDIGOLO, F. M. O processo de análise de assunto na catalogação de livros em bibliotecas universitárias: aplicação do protocolo verbal. 2014. 262 f. Tese (Doutorado em Ciência da Informação) - Faculdade de Filosofia e Ciências, Universidade Estadual Paulista, Marília, 2014. Disponível em: http://hdl.handle.net/11449/110386. Acesso em: 1 abr. 2019.

RUBI, M. P. Política de indexação na perspectiva do conhecimento organizacional. 2004. 135 f. Dissertação (Mestrado em Ciência da Informação) - Faculdade de Filosofia e Ciências, Universidade Estadual Paulista, Marília, 2004.

RUBI, M. P.; FUJITA, M. S. L. O ensino de procedimentos de política de indexação na perspectiva do conhecimento organizacional: uma proposta de programa para a educação à distância do bibliotecário. Perspectivas em Ciência da Informação, Belo Horizonte, v. 11, n. 1, p. 1-16, 2006. Disponível em: http://portaldeperiodicos.eci.ufmg.br/index.php/pci/article/viewFile/445/256. Acesso em: 7 set. 2018.

SANTA ANNA, J.; CALMON, M. A. M.; CAMPOS, S. O. Representação documentária em diferentes bibliotecas: o tratamento informacional como um processo plural. Revista ACB: Biblioteconomia em Santa Catarina, Florianópolis, v. 21, n. 1, p. 61-75, dez./mar., 2016. Disponível em: https://revista.acbsc.org.br/racb/article/view/1151/pdf. Acesso em: 30 maio 2017.

SOUSA, B. P.; FUJITA, M. S. L. Análise de assunto no processo de indexação: um percurso entre teoria e norma. Informação \& Sociedade: Estudos, João Pessoa, v. 24, n. 1, p. 19- 34, jan./abr. 2014.

SOUZA, F. P.; HILLESHEIM, A. I. A. Tratamento da informação e o uso das tecnologias da informação e comunicação. Biblionline, v. 10, p. 2, 2014. Disponível em:

http://www.periodicos.ufpb.br/ojs/index.php/biblio/article/view/16748. Acesso em: 1 abr. 2019.

SVENONIUS, E. The intellectual foundation of information organization. Cambridge: MIT, 2000. 


\title{
THE USE OF INDEXING LANGUAGES BY BRAZILIAN UNIVERSITY LIBRARIES
}

\begin{abstract}
Introduction: Indexing languages are intended to achieve vocabulary control in library catalogs according to the organization and retrieval of information. This work is configured in an analytical study on the use of indexing languages in Brazilian university libraries. Objective: A broad perspective of the use of vocabulary control tools when investigating how Brazilian university libraries use indexing languages. Methodology: Exploratory research method using a questionnaire as a data collection instrument. Elaboration of analysis categories based on the answers obtained and the objectives outlined. Results: A total of 46 responses were obtained through the application of the questionnaire. Responses were recovered from all Brazilian states. Conclusions: Libraries are aware of the importance of vocabulary control, as most of them use indexing language in the treatment of information. However, it requires the establishment of consistent procedures when the term is not found in the language used.
\end{abstract}

Descriptors: Information Organization. Indexing language. Vocabulary control. University libraries.

\section{EL USO DE LENGUAJES DE INDEXACIÓN POR LAS BIBLIOTECAS UNIVERSITARIAS BRASILEÑAS}

\begin{abstract}
RESUMEN
Introducción: Los lenguajes de indexación están destinados a lograr el control del vocabulario en los catálogos de la biblioteca de acuerdo con la organización y la recuperación de la información. Por lo tanto, este trabajo se configura en un estudio analítico sobre el uso de lenguajes de indexación en las bibliotecas universitarias brasileñas. Objetivo: Una amplia perspectiva del uso de herramientas de control de vocabulario al investigar cómo las bibliotecas universitarias brasileñas usan lenguajes de indexación. Metodología: Método de investigación exploratoria utilizando un cuestionario como instrumento de recolección de datos. Elaboración de categorías de análisis basadas en las respuestas obtenidas y los objetivos planteados. Resultados: Se obtuvieron un total de 46 respuestas mediante la aplicación del cuestionario. Se recuperaron respuestas de todos los estados brasileños. Conclusiones: las bibliotecas son conscientes de la importancia del control del vocabulario, ya que la mayoría de ellas utilizan lenguaje de indexación en el tratamiento de la información. Sin embargo, requiere el establecimiento de procedimientos consistentes cuando el término no se encuentra en el lenguaje utilizado.
\end{abstract}

Descriptores: Organización de la información. Lenguaje de indexación. Control de vocabulario. Bibliotecas universitarias.

Recebido em: 24.03.2020

Aceito em: 15.12 .2020 